\title{
O "CORINGA" COMO PARTIDA PARA ANÁLISE DA SAÚDE MENTAL NO BRASIL
}

\author{
Fernando Shimidt de Paula* \\ ANDERSON SILVA DE LIMA** \\ LUANA DA CONCEIÇÃo SILVA*** \\ TAMARA SOUSA ${ }^{* * * *}$ \\ WERTON MEDEIROS $* * * * *$
}

\section{RESUMO}

O presente artigo científico foi elaborado com o objetivo de avaliar se e quanto a saúde mental impacta na criminalidade da sociedade brasileira. A partir da análise do filme Joker (Coringa, no Brasil), produção norteamericana de 2019, alunos do curso de Direito (Anderson Silva de Lima e Werton Medeiros) e Psicólogas graduadas pela Universidade Metodista de São Paulo (Luana da Conceição Silva e Tamara Sousa), coordenados pelo professor responsável (Fernando Shimidt de Paula), analisaram a legislação e conceitos da psicologia com o propósito de chegar a alguma relação entre saúde mental e criminalidade. Os resultados, por óbvio, revelaram que a inclusão social evita a criminalidade.

Palavras-chave: Direito Penal Constitucional; Saúde pública; Inclusão social.

\section{THE "JOKER" AS A MATCH FOR MENTAL HEALTH ANALYSIS IN BRAZIL}

\section{ABSTRACT}

This scientific article was designed to assess whether and how much mental health impacts criminality in Brazilian society. Based on the analysis of the movie Joker (Coringa, Brazil), 2019 North American production, law students (Anderson Silva de Lima e Werton Medeiros) and Psychologists graduated from the Methodist University of São Paulo (Luana da Conceição Silva e Tamara Sousa), coordinated by the responsible professor (Fernando Shimidt de Paula), analyzed the legislation and concepts of psychology in order to reach some relationship between mental health and crime. The results, of course, revealed that social inclusion prevents crime.

Keywords: Criminal Law; Femicide Law; Transsexuality; Jurisprudence.

* Mestre em Direito Penal pela PUC/SP, Especialista em Gestão do Comportamento pela UNIFESP e em Direito Público pela EPM. Professor da ACADEPOL/SP e da Universidade Metodista de São Paulo. E-mail: feshipa@gmail.com

** Bacharel em Direito pela Universidade Metodista de São Paulo. Email:andersonlima1983@hotmail.com

*** Psicóloga graduada pela Universidade Metodista de São Paulo. E-mail: ludeepcl@gmail.com

**** Psicóloga graduada pela Universidade Metodista de São Paulo. E-mail: ttamarasousa@gmail. com

***** Bacharel em Direito pela Universidade Metodista de São Paulo. E-mail: wertocosta@gmail.com 


\section{INTRODUÇÃO}

Para Morgan (1956), a Psicologia enquanto ciência estuda a relação do funcionamento mental (funções e estruturas psicológicas) e sua expressão nocomportamento, considerando que a relação humana e o mundo psíquico se revestem de complexidades e, para Gazzaniga e Heatherton (2005), o escopo da Psicologia é promover uma visão integral do homem, considerando todas as variáveis e processos associados na mente (psiquismo), corpo e vida social.

Para compreender o conceito de saúde é preciso ponderar que este ficou relacionado ao conceito de normalidade, sendo modificado conforme o momento histórico vivenciado, a afirmação do que é o normal e o patológico é complexa e marcada por controvérsias (ALMEIDA FILHO, 2000).

Para a Organização Mundial da Saúde (OMS, 1946) a saúde deve ser entendida como o completo bem-estar físico, mental e social, isso não significa que o indivíduo estará livre de conflitos, o conflito é inerente à natureza humana e a saúde é uma questão multifatorial, resultado de uma interação complexa entre fatores culturais, sociais, psicológicos, físicos, biológicos e espirituais e a sua manutenção implica vários processos psicossociais na interação entre o sujeito, o sistema de saúde e a sociedade.

Na história, identificamos que os que não eram tidos como normais eram nomeados loucos e a "loucura" passou a ser considerada parte da Medicina apenas a partir do século XVIII, com a criação de instituições terapêuticas, mas que tinham uma atuação de contenção e prevenção social, afastando os enfermos do convívio social e institucionalizando-os, retirando-lhes a autonomia pessoal e analisando apenas se eles poderiam ou não conviver em sociedade (SILVEIRA; BRAGA, 2005).

Embora séculos tenham se passado e muitas mudanças no trato dos consideradosdoentes mentais foram realizadas, temos ainda uma sociedade excludente e no filme "Coringa" de Todd Phillips, que estreou em 2019, é possível acompanhar a história de Arthur Fleck, inserido em uma sociedade permeada pela desigualdade social, pelaviolência e o descaso político, principalmente em relação a saúde da população, a mãe do personagem demonstra sinais e sintomas de incapacidade física e mental e é cuidada apenas por ele, que também precisa dar conta de suas questões intrínsecas, como seu sofrimento psíquico, a dificuldade para se relacionar, manter relações afetivas e ter uma vida funcional.

Nesse trabalho, a Psicologia e o Direito buscarão desmistificar dogmas e fantasias relacionados à saúde mental e aos direitos constitucionais, utilizando do filme "Coringa" como forma de compreensão dos fenômenos mentais, emocionais e comportamentais, analisando de forma sistemática os fatos apresentados, assim como osdesdobramentos e entendendo como a ciência realiza um diagnóstico preciso,considerando a percepção de alunos universitários do curso de Direito da Universidade Metodista de São Paulo em relação a interface da Psicologia e o Direito Penal acerca da saúde mental, estabelecendo um diálogo entre expositores e público convidado, utilizando como instrumento o Estudo longitudinal, método 
de pesquisa que visa analisar as variações nas características dos mesmos elementos amostrais ao longo de um período de tempo.

\section{ASPECTOS JURIDICOS DA SAÚDE MENTAL NO BRASIL}

A vida em sociedade prevê cessão de parte dos direitos individuais em prol do interesse coletivo e issto se faz por meio do ordenametno jurídico. Agora traremos os direitos e garantiais fundamentais dos cidadãos em nosso país.

\section{DIREITOS E GARANTIAS FUNDAMENTAIS - O SER HUMANO COMO CENTRO DOORDENAMENTO JURÍDICO}

Segundo Martins (2020), a Constituição Federal de 1988 adota a nomenclatura “Direitos e Garantias Fundamentais" (Título II, Capítulos I e II) para expressar os diversos direitos e garantias individuais de maneira inédita na história do constitucionalismo brasileiro, a seguir uma tendência mundial: a Constituição de Portugal de 1976 (Parte I, Título I), a Constituição da Espanha de 1978 (Título I) e a Lei Fundamental da Alemanha de 1949 (Capítulo I). Topograficamente, encontra-se no início do documento e é um dos primeiros e principais temas constitucionais.

Ensina Martins (2020) que a opção do legislador constituinte não foi à toa ou formal, houve clara opção por dirigir a interpretação constitucional a partir da pessoa humana como centro das preocupações e não mais a organização do Estado, com suas estruturas e competências. Não por acaso, ao final do intenso processo de debates e elaboração, recebeu do presidente da Assembleia Nacional Constituinte, Ulisses Guimarães, a alcunha de "Constituição cidadã".

O comando constitucional funcionaria então como verdadeiro vetor legislativo e da atividade jurídica, estabelecendo as bases da atuação do legislador infraconstitucional e, por outro lado, dos operadores do Direito, de maneira a concretizar e buscar a eficácia desejada na Carta de 1988. A elaboração de normas e sua interpretação devem contemplar o homem como portador de uma dignidade de per si,ou seja, sem qualquer viés utilitarista.

Para Piovesan (2012), é possível ler pela reaproximação da ética, do Direito e pela força normativa dos princípios, especialmente pela dignidade da pessoa humana. A autora resgata lição conhecida: as pessoas devem existir como um fim em si mesmo e jamais como meio, como uma coisa utilizável. Conclui pelo valor da dignidade da pessoa humana e valor dos direitos e garantias fundamentais como opções que incorporam as exigências de justiça e dos valores éticos, conferindo suporte axiológicoa todo o sistema jurídico brasileiro.

Carl Schmitt (1954) apud Bonavides (2016) resgata a essência do conceito de direitos fundamentais, elaborado por Carl Schmitt, a considerar que esses direitos pertencem ao homem livre e isolado, direitos que possui em face do Estado,

Segundo Mendes e Branco (2018), parte desses direitos, sobretudo os direitos fundamentais positivos, são expressos em prestações materiais, cujo adimplemen- 
to está a cargo do Estado, sem olvidar da busca pela eficácia no meio social. Pugnam os autores pela atuação do Estado em atuar, dar ou fazer a prestação estatal, se essa for compreendida como um direito fundamental, com a finalidade de atenuar desigualdades na sociedade. $O$ direito à educação, a saúde, a alimentação, o trabalho, a moradia, o transporte, o lazer, a segurança, a previdência social, a proteção à maternidade e à infância e a assistência aos desamparados figuram como direitos expressos e resultado axiológico dos princípios antes abordados.

\section{O ESTADO PROVEDOR - O DIREITO À SAÚDE}

O direito à saúde consta expresso na Constituição Federal como espécie de direitos fundamentais e sociais. O artigo 196 da mesma Constituição dispõe: “A saúde é direito de todos e dever do Estado, garantido mediante políticas sociais e econômicas que visem à redução do risco de doença e de outros agravos e ao acesso universal e igualitário às ações e serviços para a promoção, proteção e recuperação".

É certo que a eficácia desse comando programático requer organização e recursos financeiros consideráveis, porém não há que se questionar sua existência bem assim do arcabouço normativo vinculante da ação estatal à prestação do serviço desaúde à população.

O Poder Executivo, moroso em oferecer as condições adequadas de vida àpopulação, não raro aguarda a judicialização para ver solucionado o equilíbrio entre os comandos normativos e a implantação dos mesmos direitos sociais.

Assim é porque a capacidade de ofertar determinados direitos requer um denso conteúdo administrativo e financeiro, muitas vezes limitado pela "reserva do possível", argumento traduzido, segundo Celso de Mello na ADPF 45:

Capacidade de realização dos direitos sociais, econômicos e culturais - além de caracterizar-se pela gradualidade de seu processo de concretização - depende, em grande medida, de um inescapável vínculo financeiro subordinado às possibilidades orçamentárias do Estado, de tal modo que, comprovada, objetivamente, a incapacidade da pessoa estatal, desta não se poderá razoavelmente exigir, então, considerada a limitação material referida, a imediata efetivação do comando no texto da Carta Política (MELLO, CELSO DE., ADPF 45).

Entretanto, há que se ponderar caso a caso. Mendes (2017), assentou que:

(...). O estudo do direito básico à saúde leva a concluir que os problemas de eficácia social desse direito fundamental devem-se muito mais a questões ligadas à implementação e manutenção das políticas públicas de saúde já existentes - o que implica também a composição dos orçamentos dos entes da federação - do que a falta de legislação específica. Em outros termos, o problema não é a de existência, mas de execução (administrativa) das políticas públicas dos entes federados. (MENDES, 2017, p. 697). 
Dizer de saúde implica em dizer da saúde integral do ser humano. Gozar de saúde e de uma vida digna são direitos do ser humano e obrigação do Estado. O mínimoexistencial, ficção jurídica que ilustra o conjunto de condições mínimas de existência, traduz essa exigência de prestações positivas do Estado frente ao homem. A filosofia da Carta Maior é a de um Estado social.

O presente artigo carrega uma reflexão sobre o direito à saúde daqueles que possuem um transtorno mental no Brasil. Sopesados os direitos e as limitações e ineficiências do Estado, vê-se inescapável o amparo devido àqueles sujeitos.

Decisão que apreciou o direito fundamental à saúde dos portadores de saúde mental foi relatada pelo Min. Ricardo Lewandowski em 2017. Veja-se:

O direito fundamental à saúde dos portadores de transtornos mentais encontraarrimo não somente nos arts. 5, 6º 196 e 197 da Carta da República, como também nos arts. $2^{\circ}$, $\S 1^{\circ}$, e $6^{\circ}$, I, d, da Lei 8.080/1990, na Portaria 3.916/1998 do Ministério da Saúde, além dos arts. 2 $3^{\circ}$ e 12 da Lei 10.216/2001, que, conforme visto, redireciona o modelo assistencial em saúde mental no Brasil. A linha de argumentação desenvolvida pelo Estado requerido quanto à insuficiência orçamentária é inconsistente, porquanto comprovado que os recursos existem e que foram repassados pela União, não se podendo opor escusas relacionadas com a deficiência de caixa. Comprovação nos autos de que não se assegurou o direito à saúde dos portadores de transtornos mentais no Estado do Pará, seja da perspectiva do fornecimento de medicamentos essenciais ao seu tratamento, seja no que diz respeito à estrutura física e organizacional necessárias à consecução dos objetivos previstos pelo legislador constitucional e também pelo ordinário ao editar a Lei 10.216/2001. A hipótese dos autos não cuida de implementação direta de políticas públicas, mas, sim, de cobrança realizada diretamente pela União, com fundamento na competência constitucional concorrente, para que os requeridos cumpram a sua parcela de responsabilidade no atendimento da política nacional de assistência aos pacientes com transtornos mentais. A omissão dos réus em oferecer condições de saúde dignas aos portadores de transtornos mentais exigiu a intervenção do Judiciário, tal como solicitado pela União para que, pelo menos, o núcleo essencial da dignidade da pessoa humana lhes seja assegurada, não havendo margem para qualquer discricionariedade por parte das autoridades locais no tocante a esse tema, ainda mais quando demonstrados os repasses do Executivo federal para a concessão desse mister. Os usuários dos serviços de saúde, no caso, possuem direito de exigir de um, de alguns ou de todos os entes estatais o cumprimento da referida obrigação e, na hipótese, a União demonstrou que fez a sua parte, com o que se credenciou a cobrar dos requeridos a observância de suas obrigações. Os argumentos lançados nos agravos não sãoinéditos e já foram devidamente sopesados. A própria dedução de pedido alternativo de simples dilação de prazo para o adimplemento das medidas impostas indica que o recurso apresentado não deve prosperar. Ademais, ficaram bem divisadas as esferas de responsabilidade da União e da parte ré no atendimento aos portadores de transtornos mentais. Análise exaustiva do acervo probatório, tanto da perspectiva da falta de medicamentos quanto no que 
se refere a instalações físicas, passando, ainda, pela reiteração de comportamento omisso por parte dos réus em oferecer condições de saúde dignas aos portadores de transtornos mentais. Assim, contrariamente ao sustentado pelas agravantes, in casu, o Judiciário está plenamente legitimadoa agir, sobretudo em benefício dos portadores de transtornos mentais, pessoasvulneráveis que necessitam do amparo do Estado. Prazo razoável fixado para a adoção de medidas de extrema importância para o atendimento dos portadores de deficiência mental e a multa bem aplicada em patamar proporcional para estimular o cumprimento da obrigação, sem prejudicar a prestação pela parte ré de outras políticas públicas.[ACO 1.472 AgR- segundo, rel. min. Ricardo Lewandowski, j. 1ㅇ-9-2017, P, DJE de 18-9- 2017.]

Segundo Silva (2017), é espantoso mesmo constatar que um bem tão relevante à vida humana apenas agora seja elevado à condição de direito fundamental do homem. De fato, uma vida vivida sem a qualificação do gozo de direitos fundamentais e, conforme o ilustre constitucionalista, privada do direito à saúde, não pode atualmente ser tida como usufruída em uma sociedade minimamente civilizada.

\section{O ORDENAMENTO AFETO À SAÚDE: UMA LINHA DO TEMPO}

Os direitos sociais, que diferem da concepção de direitos individuais no que tange sua destinação, são prestações positivas do Estado visando proporcionar à coletividade os meios necessários à sua subsistência.

Conforme leciona José Afonso da Silva (2017):

Assim, podemos dizer que os direitos sociais, como dimensão dos direitos fundamentais do homem, são prestações positivas proporcionadas pelo Estado direta ou indiretamente, enunciadas em normas constitucionais, que possibilitam melhores condições de vida aos mais fracos, direitos que tendema realizar a igualização de situações sociais desiguais. São, portanto, direitos que se ligam ao direito de igualdade (SILVA, 2017, p. 286).

Tais direitos, previstos no artigo $6^{\circ}$ da Constituição Federal, remontam à noção de direitos fundamentais, isto porque estão voltados às ações afirmativas do poderpúblico para que o indivíduo possa usufruir das condições mínimas em sociedade. Em outras palavras, é um mandamento constitucional essencial à consecução de um fim maior, qual seja, o direito à vida.

De acordo com Luís Roberto Barroso (2020, p. 186), “A doutrina contemporânea desenvolveu o conceito de mínimo existencial, que expressa o conjunto de condições materiais essenciais e elementares cuja presença é pressuposta à dignidade de qualquer pessoa". Este princípio, já tratado aqui anteriormente, atua em todo o ordenamento jurídico como norteador para a garantia de direitos indispensáveis ao ser humano (vide art. $5^{\circ}, \S 2^{\circ}$ da Constituição Federal). 
Nesse sentido, o supracitado dispositivo da Lei Maior estipula a saúde como um direito social. E vai além. O texto constitucional determina as medidas a serem adotadaspara o cumprimento da lei, no sentido de torná-la efetiva. Desta feita, o diploma ora mencionado traça as diretrizes de atuação obrigatória dos entes públicos visando assegurar estas prerrogativas.

Destarte, o art. 196 da Constituição Federal é expresso neste sentido: “A saúde é direito de todos e dever do Estado garantido mediante políticas sociais e econômicas que visem à redução do risco de doença e de outros agravos e ao acesso universal e igualitário às ações e serviços para sua promoção, proteção e recuperação". (BRASIL, CF, 1988. - grifo nosso).

A saúde é gênero, da qual faz parte a saúde mental. Esta, por sua vez, ganhou grande notoriedade nas sociedades contemporâneas devido às inúmeras transformações engendradas no mundo globalizado em decorrência da gama de informações às quais os indivíduos estão expostos. Ademais, os infortúnios por eles vivenciados, seja de ordem econômica ou social, catalisaram de forma espantosa os problemas psicológicos.

De acordo com Zygmunt Bauman (2007, p. 30) “Num mundo assim, não restam muitos fundamentos nos quais os indivíduos em luta possam construir suas esperanças de resgate e a que possam recorrer em caso de fracasso pessoal". Dito de outro modo, o dinamismo dos tempos atuais é tamanho que as pessoas se tornaram incapazes de lidar com seus próprios dramas e aflições, fato este que, somado às mazelas da sociedade, acabam por desencadear uma sobrecarga emocional por vezes difícil de ser assimilada pela mente humana.

No que diz respeito ao Brasil, o tema afeito aos problemas mentais antigamente era tratado de forma estigmatizante, uma vez que o indivíduo assim considerado era afastado da sociedade como forma de proteção às pessoas "normais", o que se realizava por meio de internações manicomiais. Um exemplo emblemático era o do Hospital Colônia de Barbacena, no qual internava-se pessoas com transtornos diversos e sem qualquer diagnóstico comprobatório para tanto.

O problema ganhou novo enfoque com o advento da Reforma Psiquiátrica, proporcionada pela promulgação da Lei 10.216/2001. Isto só foi possível graças aos inúmeros debates suscitados na década anterior, dando primazia à tratamentos mais humanizados, o que viria à desaguar em um modelo de assistência à saúde mental.

Esta mudança de paradigma preferiu dar primazia à prevenção dos problemas mentais ao invés das internações. Nesse sentido, reza o art. $4^{\circ}$ do supracitado diploma: "A internação, em qualquer de suas modalidades, só será indicada quando os recursos extra-hospitalares se mostrarem insuficientes" (BRASIL, 2001).

Tal dispositivo está em consonância com o que dispõe o art. 198 da Constituição, que assim dispõe:

Art. 198. As ações e serviços públicos de saúde integram uma rede regionalizada e hierarquizada e constituem um sistema único, organizado de acordo com as seguintes diretrizes: I - descentralização, com direção única em cada esfera de governo; II - atendimento integral, com prioridade para as atividades preventivas, sem prejuízo dos serviços assistenciais; III -participação da comunidade (BRASIL, CF, 1988). 
Estas medidas de prevenção e tratamento se tornaram cada vez mais insurgentes em uma sociedade assolada por pessoas que sofrem de algum tipo de transtorno mental. Daí a importância do Sistema Único de Saúde - SUS - em cumprir este papel, sendo de suma importância a capacitação de pessoal e investimentos maciços na área da saúde pública.

\section{O ESTADO DE COISAS}

O estado de coisas inconstitucionais caracteriza-se pela violação reiterada de direitos fundamentais, seja por ação ou omissão, dos órgãos competentes do Poder Público à concretizá-los, de acordo com os ditames da ordem constitucional.

Da lição de Carlos Alexandre de Azevedo Campos (2015) extrai-se:

- a constatação de um quadro não simplesmente de proteção deficiente, e sim de violação massiva, generalizada e sistemática de direitos fundamentais, que afeta a um número amplo de pessoas; (II) - a falta de coordenação entre medidas legislativas, administrativas, orçamentárias e até judiciais, verdadeira "falha estatal estrutural", que gera tanto a violação sistemática dos direitos, quanto a perpetuação e agravamento da situação; (III) - a superação dessas violações de direitos exige a expedição de remédios e ordens dirigidas não apenas a um órgão, e sim a uma pluralidade destes - são necessárias mudanças estruturais, novas políticas públicas ou o ajuste das existentes, alocação de recursos etc. (CAMPOS, 2015, p. 2).

Este conceito se deu por ocasião do julgamento da ADPF 347 no STF, que assim declarou o sistema prisional brasileiro, pela sua situação calamitosa e, de acordo com muitos juristas, insustentável.

É perfeitamente cabível essa tese no campo da saúde mental, vez que o tema é complexo e pouco se faz para a melhoria deste quadro. Vale lembrar que, de acordo com dados do Ministério da saúde, só no Brasil morrem onze mil pessoas em decorrência de suicídio por ano, sendo a quarta maior causa de óbitos entre nós.

No Brasil a questão ainda é muito estigmatizada, mas os números comprovam a urgência em se adotar ações coordenadas entre o Poder Público e a sociedade que busquem a prevenção.

\section{EFICÁCIA E MATERIALIZAÇÃO DOS DIREITOS DOS SUJEITOS PORTADORES DE DESVIOS MENTAIS}

De acordo com o arts. $1^{\circ}$ e $6^{\circ}$ da Lei $n^{\circ} 4657 / 1942$ (Lei de Introdução às Normas do Direito Brasileiro - LINDB), a lei em vigor terá efeito imediato e geral a partir desua publicação. É a chamada eficácia jurídica ou técnica, ficando a partir de então apta aproduzir seus efeitos jurídicos. Já a "eficácia sociológica ou social considerar-se-áeficaz a norma que encontrar na realidade social e nos valores positivos as condições de sua obediência" (DINIZ, 2017, p. 244). 
$\mathrm{O}$ art. $6^{\circ}$ da Constituição Federal, que trata entre outros do direito à saúde, é norma com eficácia plena e aplicabilidade imediata, ou seja, está apta a produzir seus efeitos. Caracteriza-se também por norma de ordem pública, ou seja, de comandoobrigatório, como preconiza o art. 197 da Carta Magna:

Art. 197. São de relevância pública as ações e serviços de saúde, cabendo ao Poder Público dispor, nos termos da lei, sobre sua regulamentação,fiscalização e controle, devendo sua execução ser feita diretamente ou atravésde terceiros e, também, por pessoa física ou jurídica de direito privado. (BRASIL, CF, 1988. Grifo nosso).

A materialização de direitos na Constituição está atrelada ao seu valor estruturante, não se voltando apenas para o que está expresso no texto de lei, mas também (e principalmente) aos princípios que o moldaram. Neste diapasão, o princípio da dignidade da pessoa humana tem atenção especial no ordenamento jurídico pátrio.

Vejamos o exposto por Luís Roberto Barroso (2020):

(...) é a partir do núcleo essencial do princípio da dignidade da pessoa humana que se irradiam todos os direitos materialmente fundamentais, que devem receber proteção máxima, independentemente de sua posição formal, da geração a que pertencem e do tipo de prestação a que dão ensejo (BARROSO, 2020,p. 185-186).

Diante disso, podemos dizer que a materialização dos direitos dos portadores de transtornos mentais guarda correlação com a eficácia social, uma vez que sua efetivaçãoestá subordinada à concretude dos ditames constitucionais relacionados à saúde mental. Em suma, é o direito de ter uma vida digna e saudável.

\section{O FILME “CORINGA" E A SAÚDE MENTAL NO BRASIL}

Visando a substituição do modelo baseado no hospital psiquiátrico, a política de saúde mental brasileira foi iniciada na década de 1980, com o objetivo de apresentar umnovo sistema de serviços baseado na comunidade e na proteção dos direitos humanosdas pessoas com transtorno mental (MATHES; SILVA, 2012; ALMEIDA, 2019).

Retrospectivamente, Dalgalarrondo (2005) afirma que no Brasil as primeiras ações relacionadas a saúde mental ocorreram em torno de 1841 com a criação do primeiro hospício no Rio de Janeiro, porém este desempenhava um papel excludente, com o objetivo de retirar os loucos e mendigos do convívio social, afirmando que eles causavam perturbação social, entretanto, ao interná-los não havia separação dos doentesmentais e os perturbadores.

Segundo o autor (2005), é importante ressaltar que na época as pessoas eram consideradas loucas quandonão agiam de acordo com o que era considerado normal e o tratamento indicado era a sua retirada do convívio social 
Somente em 1960 começaram os debates sobre a necessidade de mudanças na assistência psiquiátrica, buscando a humanização dos hospitais e se exigindo alterações no trato do indivíduo em sofrimento psíquico, garantindo-lhe a cidadania, o respeito aos seus direitos, à sua individualidade e autonomia (DALGALARRONDO, 2005)

Com efeito, no final dos anos 1970 o Brasil experimentava uma política nacionalde saúde mental baseada em uma grande quantidade de hospitais psiquiátri$\cos$, mas combaixa qualidade e que, por isso, frequentemente violavam os direitos humanos (ALMEIDA, 2019).

Esses fatos, intoleráveis, resultaram em movimentos sociais que, associados à onda dos direitos humanos, culminaram na Reforma Psiquiátrica, garantindo-se uma nova Política de Saúde Mental em nosso país. Com isso, houve controle sobre oshospitais psiquiátricos, redução de leitos e disponibilização de uma rede de serviços alternativos para substituição das internações. Na prática, a política tinha como foco a substituição progressiva dos hospitais psiquiátricos por Centros de Atenção Psicossocial - CAPS (MATHES; SILVA, 2012; ALMEIDA, 2019).

Segundo Mângia (2008), nesse processo identificam-se duas vertentes de enfrentamento: a tecnocrática, priorizando ações de influência na atuação dos profissionais que lidam com os doentes mentais, como desativação das celas fortes, proibição do eletrochoque e de novas internações; e a comunitária, preocupada com a participação dos doentes mentais e de seus familiares no processo de mudança. Cabe destacar que a desinstitucionalização não se restringe a deslocar para a comunidade o centro da atenção, em contrapartida do hospício ou do manicômio, ainda que, como realidade concreta, esse seja o ponto principal desse processo de mudança da percepção da loucura e do tratamento do paciente (HIRDES, 2009).

Conforme a Resolução $\mathrm{n}^{\circ} 8$ do Conselho Nacional dos Direitos Humanos (2019), em 2005 eram 40.942 leitos psiquiátricos e em dezembro de 2016, os registros do Cadastro Nacional de Estabelecimentos de Saúde (CNES) computavam 25.097 leitos. Em paralelo, a quantidade de CAPS subiu de 424 em 2005, para 2.500 em 2019 (BRASIL, 2019).

Para findar os princípios da Reforma Psiquiátrica Brasileira, a Lei $\mathrm{n}^{\circ}$ 10.216/2001 dispõe sobre a proteção e os direitos das pessoas com transtornos mentais, redirecionando o modelo assistencial em saúde mental, ao assegurar constitucionalmente que elas tenham acesso (1) ao melhor tratamento do sistema de saúde, conforme suas necessidades; (2) sejam tratadas com humanidade e respeito, no interesse exclusivo de beneficiar sua saúde, visando alcançar sua recuperação pela inserção na família, no trabalho e na comunidade; (3) sejam protegidas contra qualquer forma de abuso e exploração; (4) tenham garantia de sigilo nas informações prestadas; (5) tenham direito à presença médica, em qualquer tempo, para esclarecer a necessidade ou não de sua hospitalização involuntária; (6) tenham livre acesso aos meios de comunicação disponíveis; (7) recebam o maior número de informações a respeito de sua doença e de seu tratamento; (8) sejam tratadas em ambiente terapêutico pelos meios menos invasivos 
possíveis; e (9) sejam tratadas, preferencialmente, em serviços comunitários de saúde mental (BRASIL, 2001).

Conforme Almeida (2019, p. 2) "O desenvolvimento da política de saúde mental no Brasil esteve estreitamenteassociado à criação do Sistema Único de Saúde (SUS), à descentralização da administração da saúde no país, à mobilização de profissionais e a mudanças sociais e culturais da sociedade brasileira"

Com isso, é possível afirmar que saúde mental é uma área de conhecimento e de atuação interdisciplinar no âmbito das políticas públicas de saúde de forma preventiva, promoção e manutenção da saúde da população (MEDEIROS; GUIMARÃES, 2002).

Barlow (2008) define o transtorno psicológico como uma disfunção psicológica do indivíduo, uma desordem no funcionamento cognitivo, emocional ou comportamental, associada ao sofrimento ou prejuízo no funcionamento e/ou resposta não atípica ou culturalmente não esperada, caracterizados por uma combinação de comportamentos, pensamentos e emoções que afetam as relações afetivas e a capacidade de produtividade, cujo diagnóstico deve ser realizado a partir das orientações do Manual Diagnóstico e Estatístico de Transtornos Mentais (DSM-V, 2014), que avalia a frequência em que o indivíduo apresenta os sinais e sintomas, a duração dos sinais e sintomas e se há outra condição justificante. Os sinais e sintomas apresentados devem satisfazer todos os critérios de um transtorno psicológico.

No filme em tela, "Coringa", não é informado o diagnóstico do personagem Arthur Fleck, mas é possível analisar sinais e sintomas de comportamentos atípicos em relação ao seu aspecto físico, relações afetivas frágeis e abusivas, a dependência química, os desejos reprimidos, as alucinações, a agressividade, entre outros.

Seu comportamento atípico é recorrentemente questionado ou verbalizado sempre que possível por aqueles que têm contato com ele; não há evidência de que foi fornecido um atendimento adequado, com acompanhamento psicossocial e de umaequipe multidisciplinar como orientado pela OMS (2001), que afirma que o ambiente social é uma importante determinante do resultado do tratamento, visto que quando for favorável, o ambiente social contribui para a recuperação e reintegração; se desfavorável, pode reforçar a estigmatização e a discriminação.

A realidade no Brasil não parece tão distante do filme, o acompanhamentorealizado através do CAPS se mostra insuficiente de acordo com os dados emitidos pela Agência Brasil (2020), porquanto em todo território nacional há 2.465 unidades para um total de 5.570 municípios. Além disso, a divisão não é proporcional: enquanto noSudeste há 892 unidades, no Centro-Oeste há apenas 142, sendo mais de $50 \%$ especializado no atendimento de álcool e drogas. Em relação ao atendimento para osque estão sob custódia do Estado, a precarização é mais abrangente, há apenas 26 hospitais de custódia e tratamento no território brasileiro e mais de 4 mil prisioneiros esperando uma vaga, enquanto isso seguem sem acompanhamento. 


\section{METODOLOGIA}

Aplicamos pesquisa de campo do tipo longitudional tendo como público alvo estudantes do curso de Direito da Universidade Metodista de São Paulo, num total de 100 respondentes. O questionário foi construído com 10 perguntas objetivas e aplicado em três momentos: logo após exibição do filme; logo após a apresentação da visão das psicólogas sobre o filme e logo após a apresentação dos alunos do Direitos sobre os aspectos jurídicos. Percebemos algumas variações nas respostas tendo em vista os argumentos apresentados, as quais fora relatadas em tabelas e discutidas, como adiante se verá.

\section{PARTICIPANTES}

A amostra foi composta por 100 alunos universitários, dos quais $68 \%$ do sexo feminino e $32 \%$ do sexo masculino, matriculados no curso de graduação em Direito da Universidade Metodista de São Paulo (UMESP), em faixa etária de 18 a 51 anos de idade, dos turnos matutino e noturno. A porcentagem de concentração dos participantes por faixa etária está descrita na Tabela 1. A escolha da amostra se deu por conveniência:

Tabela 1. Faixa etária da amostra:

\begin{tabular}{|c|c|c|c|c|c|c|}
\hline $\begin{array}{c}18 \text { a } 20 \\
\text { anos }\end{array}$ & $\begin{array}{c}21 \text { a } \\
25 \\
\text { anos }\end{array}$ & $\begin{array}{c}26 \text { a } \\
30 \\
\text { anos }\end{array}$ & $\begin{array}{c}31 \text { a } \\
40 \\
\text { anos }\end{array}$ & $\begin{array}{c}41 \text { a } \\
50 \\
\text { anos }\end{array}$ & $\begin{array}{l}\text { Acima } \\
\text { de } 51 \\
\text { anos }\end{array}$ & $\begin{array}{l}\text { Total } \\
\text { Geral }\end{array}$ \\
\hline $21 \%$ & $36 \%$ & $8 \%$ & $17 \%$ & $12 \%$ & $6 \%$ & $100 \%$ \\
\hline
\end{tabular}

Quanto à idade dos participantes, 21\% tinham de 18 a 20 anos; 36\% de 21 a 25 anos; $8 \%$ de 26 a 30 anos; $17 \%$ de 31 a 40 anos, $12 \%$ de 41 a 50 anos e $6 \%$ acima de 51 anos. Em todas as faixas etárias, a maior porcentagem deu-se entre 21 a 25 anos, sendo $36 \%$ da amostra total.

Tabela 2. Classe Social

\begin{tabular}{c|c|c|c|c|c}
\hline $\begin{array}{c}\text { Clas- } \\
\text { se A }\end{array}$ & $\begin{array}{c}\text { Clas- } \\
\text { se B }\end{array}$ & $\begin{array}{c}\text { Classe } \\
\text { C }\end{array}$ & $\begin{array}{c}\text { Classe } \\
\text { D }\end{array}$ & $\begin{array}{c}\text { Classe } \\
\text { E }\end{array}$ & $\begin{array}{c}\text { Total } \\
\text { Geral }\end{array}$ \\
\hline $3 \%$ & $19 \%$ & $49 \%$ & $20 \%$ & $10 \%$ & $100 \%$ \\
\hline
\end{tabular}

Em relação a classe social, 3\% dos participantes afirmam que a renda do grupo familia é acima de 20 salários mínimos, 19\% que a renda está entre 11 e 19 
salários mínimos, 49\% afirmam que a renda é de 5 a 10 salários mínimos, 20\% com renda entre 3 e 4 salários mínimos e 10\% afirmam receber até 2 salários mínimos.

\section{LOCAL}

A coleta de dados ocorreu de forma online, os respondentes recebiam através do aplicativo Whatsapp informações e orientações sobre a pesquisa e o link que deveriam clicar para serem direcionados ao Questionário de Percepção de 10 perguntas. O questionário foi confeccionado no Google Forms e a coleta de dados foi feita após os encontros online realizados nos meses de agosto e setembro de 2020.

\section{INSTRUMENTOS}

Para a coleta de dados foram utilizados os seguintes instrumentos:

- Filme "Coringa": os respondentes foram orientados a assistir ao filme para ter acesso ao questionário;

- Questionário Sociodemográfico: Elaborado a partir de questões a serem respondidas pelos participantes, tais como: escolaridade, gênero, região em que reside, faixa etária e classe social. Tais informações são necessárias para um melhor delineamento da amostra coletada;

- Questionário de Percepção: Composto por 10 questões, cada afirmação deve ser respondida a partir de 3 opções: C (concordo), "se a frase for, na maior parte das vezes verdadeira, ou se concorda com ela"; e CP (Concordo Parcialmente) se a frase for, parcialmente verdadeira ou se concordar parcialmente com ela" e NC (Não concordo) "se a frase for falsa ou se não concordar com ela".

\section{PROCEDIMENTOS}

O presente trabalho buscou compreender, a partir do filme "Coringa", aspectos da saúde mental no Brasil. Após autorização da Universidade Metodista de São Paulo e através do grupo de Estudos de Direito Penal foi possível elencar o grupo diretor, tendo como representantes do curso de Direito os alunos Anderson e Werton, ambos estudantes do $8^{\circ}$ semestre de graduação do curso de Direito e as psicólogas Luana e Tamara, sob a supervisão do professor Fernando Shimidt de Paula.

Os respondentes foram informados sobre o propósito da pesquisa e o Termo de Consentimento Livre e Esclarecido (TCLE), a amostra foi composta por conveniência, logo, o link era encaminhado e os que concordaram em participar respondiam.

O tempo médio de resposta foi de 02 minutos e 43 segundos. Cada voluntário respondeu individualmente, cujos resultados foram computados automaticamente, sem informar o nome dos respondentes, garantida a confidencialidade dos participantes e dosresultados. Após a coleta, os dados foram organizados em uma planilha e analisadoscom estatística descritiva. 


\section{ASPECTOS ÉTICOS}

A coleta de dados ocorreu após autorização da instituição de ensino, foi necessária a concordância com o Termo de Consentimento Livre e Esclarecido (TCLE) elaborado conforme as normas estabelecidas pela Resolução 466/12 do Conselho Nacional de Saúde, a qual entrou em vigor em junho de 2013. No termo constavam informações a respeito da pesquisa, dos riscos e benefícios, podendo interromper ou cancelar a sua participação a qualquer momento, não ocasionando em nenhum tipo de prejuízo para o voluntário. A privacidade e o sigilo das respostas dos participantes serãogarantidos, respeitando o que foi garantido no TCLE.

As informações coletadas foram armazenadas de forma eletrônica, cujo acesso, armazenamento e análise ficaram sob responsabilidade do grupo diretor. Todos os dadospessoais que possam identificar os participantes foram mantidos em sigilo, propiciando que o anonimato fosse mantido. Todos os materiais e dados colhidos permanecerão resguardados, nenhum material será enviado a outras instituições ou ao exterior. Todos os alunos foram informados que os resultados serão amplamente divulgados em encontros científicos, bem como através de publicações científicas, independente dos seus resultados.

\section{Análise de Dados (Estudo Longitudinal)}

A seguir serão apresentados os resultados adquiridos através do Questionário de Percepção, respondido após os 3 primeiros encontros, considerando que $C$ é Concordo, CP é Concordo Parcialmente e NC é Não Concordo.

Tabela 3. Pergunta 1. "Você concorda com a frase: “O diagnóstico psicológico é fundamental para apuração da culpabilidade do infrator da lei penal?"

\begin{tabular}{c|c|c|c}
\hline & Questionário 1 & Questionário 2 & Questionário 3 \\
\hline C & $65 \%$ & $63 \%$ & $58 \%$ \\
\hline CP & $35 \%$ & $35 \%$ & $37 \%$ \\
\hline NC & $0 \%$ & $2 \%$ & $5 \%$ \\
\hline
\end{tabular}

Tabela 4. Pergunta 2. "Você concorda com a frase: "Os medicamentos controlamcompletamente os pensamentos e comportamentos do personagem Arthur Fleck/ Coringa?"

\begin{tabular}{c|c|c|c}
\hline & Questionário 1 & Questionário 2 & Questionário 3 \\
\hline $\mathrm{C}$ & $8 \%$ & $14 \%$ & $10 \%$ \\
\hline $\mathrm{CP}$ & $54 \%$ & $58 \%$ & $53 \%$ \\
\hline $\mathrm{NC}$ & $38 \%$ & $28 \%$ & $37 \%$ \\
\hline
\end{tabular}


Tabela 5. Pergunta 3. Você concorda com a frase: “O descaso em relação à saúde mental, somada a infância conturbada, justifica e/ou contribui para todas as ações dopersonagem Arthur Fleck/ Coringa?"

\begin{tabular}{l|l|l|l}
\hline & Questionário 1 & Questionário 2 & Questionário 3 \\
\hline C & $59 \%$ & $51 \%$ & $53 \%$ \\
\hline CP & $36 \%$ & $45 \%$ & $44 \%$ \\
\hline NC & $5 \%$ & $4 \%$ & $3 \%$ \\
\hline
\end{tabular}

Tabela 6. Pergunta 4. Você concorda com a frase: “Quanto maior a vulnerabilidade social de um sujeito, maior a probabilidade dele cometer crimes?"

\begin{tabular}{l|l|l|l}
\hline & Questionário 1 & Questionário 2 & Questionário 3 \\
\hline $\mathrm{C}$ & $29 \%$ & $31 \%$ & $31 \%$ \\
\hline $\mathrm{CP}$ & $52 \%$ & $51 \%$ & $48 \%$ \\
\hline $\mathrm{NC}$ & $19 \%$ & $18 \%$ & $21 \%$ \\
\hline
\end{tabular}

Tabela 7. Pergunta 5. Você concorda com a frase: “O filme retrata a condição social de pessoas com doenças mentais na sociedade brasileira?"

\begin{tabular}{l|l|l|l}
\hline & Questionário 1 & Questionário 2 & Questionário 3 \\
\hline $\mathrm{C}$ & $13 \%$ & $11 \%$ & $13 \%$ \\
\hline $\mathrm{CP}$ & $57 \%$ & $55 \%$ & $46 \%$ \\
\hline $\mathrm{NC}$ & $30 \%$ & $34 \%$ & $41 \%$ \\
\hline
\end{tabular}

Tabela 8. Pergunta 6. Você concorda com a frase: “Todos os infratores da lei penalpossuem algum tipo de transtorno ou doença mental"?

\begin{tabular}{l|l|l|l}
\hline & $\begin{array}{l}\text { Questioná- } \\
\text { rio 1 }\end{array}$ & Questionário 2 & Questionário 3 \\
\hline $\mathrm{C}$ & $2 \%$ & $2 \%$ & $3 \%$ \\
\hline $\mathrm{CP}$ & $17 \%$ & $24 \%$ & $24 \%$ \\
\hline $\mathrm{NC}$ & $81 \%$ & $74 \%$ & $73 \%$ \\
\hline
\end{tabular}

Tabela 9. Pergunta 7. Você concorda com a frase: “O infrator da lei penal que possui transtorno mental deve ser tratado igual ao infrator da lei sem transtorno mental?"

\begin{tabular}{l|l|l|l}
\hline & $\begin{array}{l}\text { Questioná- } \\
\text { rio 1 }\end{array}$ & Questionário 2 & Questionário 3 \\
\hline $\mathrm{C}$ & $4 \%$ & $6 \%$ & $4 \%$ \\
\hline $\mathrm{CP}$ & $25 \%$ & $24 \%$ & $23 \%$ \\
\hline $\mathrm{NC}$ & $71 \%$ & $70 \%$ & $73 \%$ \\
\hline
\end{tabular}


Tabela 10. Pergunta 8. Você concorda com a frase: "A lei penal deve ser endurecida para proteger o cidadão que não comete infrações?"

\begin{tabular}{l|l|l|l}
\hline & Questionário 1 & Questionário 2 & Questionário 3 \\
\hline $\mathrm{C}$ & $47 \%$ & $54 \%$ & $55 \%$ \\
\hline $\mathrm{CP}$ & $36 \%$ & $28 \%$ & $27 \%$ \\
\hline $\mathrm{NC}$ & $17 \%$ & $18 \%$ & $19 \%$ \\
\hline
\end{tabular}

Tabela 11. Pergunta 9. Você concorda com a frase: “O Arthur Fleck/ Coringa deve ser responsabilizado judicialmente por todos os seus atos?"

\begin{tabular}{l|l|l|l}
\hline & Questionário 1 & Questionário 2 & Questionário 3 \\
\hline $\mathrm{C}$ & $31 \%$ & $39 \%$ & $38 \%$ \\
\hline $\mathrm{CP}$ & $59 \%$ & $51 \%$ & $52 \%$ \\
\hline $\mathrm{NC}$ & $10 \%$ & $10 \%$ & $10 \%$ \\
\hline
\end{tabular}

Tabela 12. Pergunta 10. Você concorda com a frase: “Todos são iguais perante a lei"?

\begin{tabular}{l|l|l|l}
\hline & Questionário 1 & Questionário 2 & Questionário 3 \\
\hline C & $30 \%$ & $27 \%$ & $26 \%$ \\
\hline CP & $35 \%$ & $38 \%$ & $38 \%$ \\
\hline NC & $35 \%$ & $35 \%$ & $36 \%$ \\
\hline
\end{tabular}

\section{DISCUSSÃO}

A amostra foi direcionada aos alunos do curso de Direito que fazem parte do grupo de estudos de Direito Penal. Após os resultados foi possível identificar que a faixa etária dos participantes apresenta maior concentração em universitários de 18 a 25 anos, totalizando $57 \%$ da amostra, sendo $68 \%$ do sexo feminino. Estes dados vão ao encontro dos dados coletados no Censo do Ensino Superior 2017 (INEP, 2018), que apontam a predominância das mulheres nas universidades e a idade média de ingresso no ensino superior os 21 anos. Em relação aos resultados do questionário, para a primeira afirmação: "Você concorda com a frase: $\mathrm{O}$ diagnóstico psicológico é fundamental para apuração daculpabilidade do infrator da lei penal?" é possível verificar que no primeiro questionárioos que Concordaram eram $65 \%$, no segundo $63 \%$ e no terceiro $58 \%$, ao passo que os que Não Concordavam aumentou de $0 \%$ para $2 \%$ no segundo questionário e $5 \%$ no terceiro questionário: podemos considerar que nos encontros realizados houve esclarecimentos em relação a forma como o diagnóstico é realizado, que o indivíduo é biopsicossocial e deve ser analisado sob influências biológicas, psicológicas e sociais, além dos esclarecimentos relacionados ao processo jurídico, amparado no Código Penal. 
Para a segunda afirmação: "Você concorda com a frase: Os medicamentos controlam completamente os pensamentos e comportamentos do personagem Arthur Fleck/ Coringa?" no primeiro questionário 8\% Concordaram; após 14\%, e no último questionário 10\%, os que Concordavam Parcialmente mudou de 54\% para $58 \%$ e por fim $53 \%$ e os que Não Concordavam mudou de $38 \%$ para $28 \%$ e para $37 \%$ : podemos perceber que após a palestra voltada para a Psicologia houve uma mudança substancial nas respostas e após a palestra voltada para o Direito uma outra mudança, de forma que o primeiro e o último questionários apresentaram percentuais mais próximos. Podemos considerar que ao longo dos encontros foi proposta uma reflexão sobre cenas específicasdo filme, no entanto o grupo diretor não utilizou as mesmas cenas e se dispôs a provocaros respondentes em relação às possibilidades de atuação da Psicologia e do Direito nas respectivas palestras, levando-se em conta que no último questionário a palestra dos alunos de Direito evidenciou os crimes praticados pelo personagem, estabelecendo que foram aumentando na medida em que o personagem ficava sem atendimento clínico e, consequentemente, sem os remédios.

Na terceira pergunta: "Você concorda com a frase: $\mathrm{O}$ descaso em relação à saúdemental, somada a infância conturbada, justifica e/ou contribui para todas as ações do personagem Arthur Fleck/ Coringa?", os resultados obtidos demonstraram que os respondentes que Concordavam eram de $59 \%$, após $51 \%$ e no último $53 \%$, os que Concordavam Parcialmente $36 \%$ para $45 \%$ e após $44 \%$ e os que Não Concordavam erade $5 \%$, foi para $4 \%$ e após $3 \%$ : podemos considerar uma mudança substancial após a palestra voltada a Psicologia, porque aspectos intrínsecos do comportamento do personagem foram abordados e uma nova mudança no terceiro questionário, pois a palestra dos alunos de Direito abordou o papel do Estado e o cumprimento da Constituição do país.

A quarta pergunta: “Você concorda com a frase: Quanto maior a vulnerabilidade social de um sujeito, maior a probabilidade dele cometer crimes?", os resultados apontaram que $29 \%$ Concordavam, após $31 \%$ e permaneceram em $31 \%$, enquanto os que Concordavam Parcialmente partiu de $52 \%$ para $51 \%$ e após $48 \%$ e os que Não Concordavam foi de $19 \%$ para $18 \%$ e depois subiu para $21 \%$. Considerando que as respostas foram computados automaticamente, sem informar o nome dos respondentes, o resultado total não considera mudança substancial após as palestras.

Na pergunta 5: "Você concorda com a frase: $O$ filme retrata a condição social depessoas com doenças mentais na sociedade brasileira?", os que Concordavam eram $13 \%$, foi para $11 \%$ e aumentou para $13 \%$, os que Concordavam Parcialmente eram $57 \%$,foi para $55 \%$ e diminuiu para $46 \%$, os que Não Concordavam era $30 \%$, foi para $34 \%$ e aumentou para $41 \%$. Após a palestra dos alunos de Direito podemos perceber que os respondentes que Concordavam Parcialmente diminuíram e os que não concordavam aumentaram; podemos considerar que nessa palestra foi abordado que o personagem ficaria sem assistência médica por decisões políticas e no Brasil o direito a saúde é assegurado pela Constituição, sendo um direito de todos e dever do Estado. 
Para a Pergunta 6. "Você concorda com a frase: "Todos os infratores da lei penalpossuem algum tipo de transtorno ou doença mental?", os resultados apontaram que os que Concordavam eram $2 \%$, mantiveram-se em $2 \%$ e após subiram para $3 \%$. Os que Concordavam Parcialmente eram $17 \%$ subiu para $24 \%$ se manteve em $24 \%$, os que Não Concordavam eram $81 \%$, baixou para $74 \%$ e para $73 \%$. Percebemos uma variação nos que Concordavam Parcialmente e Não concordavam após a palestra das psicólogas, que buscaram promover uma visão integral do indivíduo, considerando seu funcionamento psíquico, seu contexto social e cultural.

Para a pergunta 7: "Você concorda com a frase: O infrator da lei penal quepossui transtorno mental deve ser tratado igual ao infrator da lei sem transtorno mental? ", os que Concordavam eram $4 \%$ foi para $6 \%$ e após diminuiu para $4 \%$. Os queConcordavam Parcialmente eram $25 \%$ foi para $24 \%$ e baixou para $23 \%$, os que Não Concordavam era $71 \%$, foi para $70 \%$ e aumentou para $73 \%$, não demonstrando que houve mudança substancial após as palestras.

Para a pergunta 8: "Você concorda com a frase: A lei penal deve ser endurecida para proteger o cidadão que não comete infrações? ", os que Concordam eram $47 \%$, subiu para $54 \%$ e para $55 \%$, os que Concordavam Parcialmente eram $36 \%$ diminuiu para $28 \%$ e $27 \%$, os que Não Concordavam eram $17 \%$, aumentou para $18 \%$ e para $19 \%$. Podemos perceber que houve variação entre os que Concordavam e Concordavam Parcialmente, embora as leis penais não foram dissecadas ao longo dos encontros, reforçamos que é necessário ponderar acerca do comportamento dos indivíduos e suas ações para construir ou deturbar a vida em sociedade, além das ações da sociedade voltadas para os indivíduos, principalmente os marginalizados.

Para a pergunta 9: "Você concorda com a frase: O Arthur Fleck/ Coringa deve ser responsabilizado judicialmente por todos os seus atos?" , os que Concordavam eram $31 \%$, aumentou para $39 \%$ e diminuiu para $38 \%$, os que Concordavam Parcialmente era $59 \%$, após $51 \%$ e aumentou para $52 \%$, os que Não Concordavam era $10 \%$ e não houve alteração dos seguintes questionários. Podermos perceber um aumento entre os que Concordavam após a palestra das psicólogas que analisaram os sinais e sintomas que o personagem apresentava, elencando os desejos reprimidos, as alucinações e sua agressividade.

Para a pergunta 10: "Você concorda com a frase: Todos são iguais perante a lei? ", os que Concordavam eram $30 \%$, após $27 \%$ e diminuiu para $26 \%$, os que Concordam Parcialmente eram 35\% aumentou para 38\% e se manteve em 38\%, enquanto que osque Não Concordavam eram $35 \%$, manteve $35 \%$ e aumentou para $36 \%$, não havendo alteração significativa após as palestras.

Ao realizar um estudo longitudinal identificamos e até é esperado mudanças expressivas nos resultados, no entanto, nesse estudo podemos elencar que somente os resultados relacionados a saúde mental e aspectos psicológicos apresentaram alterações relevantes, a hipóteses é que o público alvo são alunos do curso de Direito de diferentes semestres, participantes do grupo de estudos de Direito Penal e a priori tiveram contato com o conteúdo em algum momento do curso ou em 
atividades do próprio grupo de estudos, bem como os preceitos da Constituição que assegura direitos sociais, entre eles a saúde.

\section{CONSIDERAÇÕES FINAIS}

A partir dos preceitos da Psicologia e do Direito, utilizando o filme "Coringa" como referência, expositores e convidados discursaram acerca da saúde mental, dos direitos constitucionais e seus reflexos na criminalidade brasileira.

Os resultados colocam em evidência o quanto o dialogo concernente ao tema saúde mental é importante, seja para desmistificar suposições do senso comum, seja para evidenciar a marginalização sistemática realizada com acometidos por psicopatologias, além de proporcionar melhor compreensão sobre áreas de conhecimento diversificadas.

É possível concluir que pessoas acometidas por psicopatologias severas têm suas relações sociais comprometidas, assim como dificuldade em estabelecer e manter uma vida funcional, mostrando-se necessário sejam assistidas e inseridas na sociedade. Embora nossa Constituição tenha como premissa o princípio da dignidade humana e a garantia dos direitos fundamentais, dentre eles o direito à saúde, em nosso dia a dia e com base no estudo realizado, podemos também concluir pela não efetividade dasações, seja pela carência dos orçamentos ou pela falta de políticas públicas factuais.

Concluímos, pois, que estudos como este se mostram cada vez mais necessários para sensibilizar e aproximar as pessoas sobre a temática de uma sociedade inclusiva. A saúde pública é um fator de suma importância para a estabilidade e desenvolvimento de uma sociedade e, mais, consideramos que seu abandono contribui para o avanço da criminalidade.

\section{REFERENNCIAS}

ALMEIDA, J. M. C. Política de saúde mental no Brasil: o que está em jogo nasmudanças em curso. Cad. Saúde Pública, n. 35, v. 11, 2019. Disponível em: $<$ https://www. scielosp.org/pdf/csp/2019.v35n11/e00129519/pt>. Acesso em:20.ago.2020.

ALMEIDA FILHO, N. O conceito de saúde: ponto-cego da epidemiologia? RevistaBrasileira de Epidemiologia, v. 3, n. 1-3, p. 4-20, 2000.

BARLOW, D. H.; DURAND, V. M. Psicopatologia: Uma abordagem integrada. São Paulo: Cengage Learning, 2008.

BARROSO, L. R. Curso de direito constitucional contemporâneo: os conceitosfundamentais e a construção do novo modelo - 9. ed. - São Paulo: Saraiva Educação,2020.

BAUMAN, Zygmunt. Tempos Líquidos. Tradução Carlos Alberto Medeiros. Rio de Janeiro: Zahar, 2007. 
BONAVIDES, Paulo. Curso de Direito Constitucional. 32. ed. atual. São Paulo:Malheiros Editores, 2017.

BRASIL. Lei $n^{\circ} 10.216$, de 06 de abril de 2001. Proteção e os direitos das pessoas portadoras de transtornos mentais. Disponível em: < http://www.planalto.gov.br/ccivil_03/ leis/leis_2001/110216.htm>. Acesso em: 20 ago. 2020.

BRASIL. Supremo Tribunal Federal. Tribunal Pleno. Agravo Regimental n. 175. Relator: Ministro Gilmar Mendes. Agravante: União. Agravados: Ministério Público

Federal; Clarice Abreu de Castro Neves; Município de Fortaleza; Estado do Ceará.Brasília, DF, 17 de março de 2010. DJe n. 76, Brasília, DF, 30 de abril de 2010.

Disponível em: http://www.stf.jus.br/arquivo/cms/noticiaNoticiaStf/anexo/STA175. pdf. Acesso em: 15 set.2020.

BRASIL. Lei $n^{0} 12.986$, de 02 de junho de 2014. Resolução $n^{\circ} 8$ do Conselho Nacional dos Direitos Humanos - CNDH. Diário Oficial da União, 14 de agosto de 2019.

BRASIL. Supremo Tribunal Federal. ADPF 45 MC/DF. Rel. Min. Celso de Mello,Pleno, Julgamento, 29/04/2004, Diário de Justiça Eletrônico, 04/05/2004.

CORINGA (Joker). Direção: Todd Phillips. Produção de Village Roadshow Pictures. Estados Unidos: Warner Bros, 2019. 1 DVD.

DALGALARRONDO, P. História das primeiras instituições para alienados no Brasil. História, Ciências, Saúde - Manguinhos, 2005.

DALGALARRONDO, P. Psicopatologia e semiologia dos transtornos mentais. 2. ed.Porto Alegre: Artmed, 2008.

DINIZ, Maria Helena. Dicionário Jurídico Universitário. 3. ed. São Paulo: SaraivaJur, 2017.

GAZZANIGA, M. S.; HEATHERTON, T. F. Ciência Psicológica: Mente, Cérebro e Comportamento. Porto Alegre: Artmed, 2005.

HIRDE, ALICE. A reforma psiquiátrica no Brasil: uma (re) visão. Ciência \& SaúdeColetiva, v. 14, n. 1, p. 297-305, 2009.

MANGIA, E. F. Psiquiatria institucional: do hospício à reforma psiquiátrica. Cadernos de Saúde Pública, Rio de Janeiro, v. 24, n. 3, 2008.

MARTINS, Flávio. Curso de Direito Constitucional. 4. ed. São Paulo: Saraiva, 2020.

MARTINS, H. Expansão da rede e redução de internação podem melhorar serviço de saúde mental. Agência Brasil. Disponível em:<https://agenciabrasil.ebc.com.br/geral/ noticia/2017-09/expansao-da-rede-e-reducao-de-internacao-podem-melhorar-servico-de-saude> Acesso em: Nov.2020. 
MATHES, P. G. SILVIA, F. B. Saúde Mental e o Campo Sociojurídico: o "estado daarte do debate" com a Reforma Psiquiátrica. Saúde Soc. São Paulo, v.21, n.3, p.529-542, 2012.

MEDEIROS, S. M.; GUIMARÃES, J. Cidadania e saúde mental no Brasil: contribuição ao debate. Ciência \& Saúde Coletiva, v. 7, n. 3, p. 571-579, 2002.

MENDES, Gilmar Ferreira; BRANCO, Paulo Gustavo Gonet. Curso de DireitoConstitucional. 12. ed. São Paulo: Saraiva, 2017.

MORGAN TC. Introduction Fo Psychology. Mcgraw-hill, New York. 1956.

NERY JUNIOR, Nelson; NERY, Rosa Maria de Andrade. Constituição Federal Comentada: legislação constitucional. 6. ed. rev. atual. e aum. São Paulo: Revista dos Tribunais, 2018.

ORGANIZAÇÃO MUNDIAL DE SAÚDE. A saúde mental pelo prisma da saúde pública. Relatório sobre a saúde no mundo 2001. Genebra: OPAS/OMS, p.1-16, 2001. Disponível em: <https:/ / www.nescon.medicina.ufmg.br/biblioteca/imagem/0205.pdf>. Acesso em: 20 ago. 2020.

PIOVESAN, Flávia. Direitos Humanos e o Direito Constitucional Internacional. 13. ed. rev. e atual. São Paulo: Saraiva, 2012.

SILVA, José Afonso da. Curso de Direito Constitucional Positivo. 40. ed. São Paulo: Malheiros Editores, 2017.

SILVEIRA, Lia Carneiro; BRAGA, Violante Augusta Batista. Acerca do conceito de loucura e seus reflexos na assistência de saúde mental. Rev. Latino-Am.Enfermagem. Ribeirão Preto, v. 13, n. 4, 2005.

STF. A Constituição e o Supremo. Disponível em http://www.stf.jus.br/portal/constituicao/artigobd.asp?item=\%201814. Acesso em11.mar.2021.

STF. A Constituição e o Supremo. Disponível em <https://www.planalto.gov.br/ccivil 03/leis/leis_2001/110216.htm >. Acesso em14.mar.2021.

STF. A Constituição e o Supremo. Disponível em <https://www.conjur.com.br/2015set-01/carlos-campos-estado-coisas-inconstitucional-litigio-estrutural>. $\quad$ Acesso em 14.mar.2021

STF. A Constituição e o Supremo. Disponível em: https://portalarquivos 2.saude.gov.br/images/pdf/2018/setembro/20/Coletiva-suic--dio.pdf. Acesso em 14.mar.2021

STF. A Constituição e o Supremo. Disponível em: http://www.planalto.go v.br/ ccivil_03/Decreto-Lei/Del4657compilado.htm. Acesso em 14.mar.2021

STF. A Constituição e o Supremo. Disponível em: <http://www.planalto.gov.br/ ccivil_03/Constituicao/ConstituicaoCompilado.htm>. Acesso em 14.mar.2021. 


\section{Apêndice A - Termo de Consentimento Livre e Esclarecido}

$\mathrm{Eu}$, consinto de minha livre e espontânea vontade participar da pesquisa respondendo ao questionário "Filme Coringa" sob a responsabilidade dos pesquisadoresFernando Shimidt de Paula, Anderson Silva de Lima, e Werton Medeiros, respectivamente Professor e alunos do curso de Direito da Universidade Metodista de São Paulo (UMESP) em parceria com as Psicólogas Luana da Conceição Silva eTamara Sousa.

Fui informado que a pesquisa faz parte do projeto de Grupo de Estudos de Direito Penal da UMESP, existente há sete anos, com 4 encontros realizados ao longodo semestre, com a finalidade de fomentar debates e discussões acerca dos aspectos jurídicos, amparados no código penal, somando a este semestre de análises psicossociaise psicopatológicos para análise do filme Coringa.

Também estou ciente que os riscos estão minimamente reduzidos por se tratar apenas de aplicação de questionários de autopreenchimento com duração de no máximo 1hora. No entanto, durante a aplicação do questionário, poderá ocorrer cansaço mental e/ou reação emocional, caso isso ocorra, o participante poderá interromper a qualquer momento e desistir, independentemente do motivo, sem sofrer dano algum e se necessário contará com o apoio em termos de atendimento e / ou orientação por partedos pesquisadores.

Enquanto participante declaro estar ciente de que poderei interromper / desistir de minha participação a qualquer momento, sem nenhum tipo de prejuízo. Como participante sei que os resultados desta pesquisa poderão oportunizar condições estratégias visando a melhora da qualidade de vida, seja direta ou indiretamente, do público envolvido nesta coleta de dados, bem como de todos aqueles em condições semelhantes.

Tenho clareza que se trata de uma pesquisa que respeita a integridade do participante, não acarretando riscos previsíveis para sua saúde, ou seja, os riscos envolvidos são mínimos. Estou ciente de que minha privacidade será totalmente preservada e as informações permanecerão em sigilo, não sendo divulgado em nenhum momento o meu nome e/ou outros dados que possam me identificar. Também autorizo que os dados coletados nesta pesquisa sejam utilizados em outras pesquisas no futuro, respeitadas as informações deste termo. Você terá acesso aos profissionais responsáveis pela pesquisa para esclarecimento de eventuais dúvidas, em qualquer momento.

São Bernardo do Campos, Setembro/ Outubro e Novembro de 2020 


\section{Apêndice B - Questionário}

- Você concorda com a frase: “O diagnóstico psicológico é fundamental para apuraçãoda culpabilidade do infrator da lei penal"?

( ) concordo totalmente

( ) concordo parcialmente() discordo

- Você concorda com a frase: "Os medicamentos controlam completamente os pensamentos e comportamentos do personagem Arthur Fleck/ Coringa"?

( ) concordo totalmente

( ) concordo parcialmente() discordo

- Você concorda com a frase: "O descaso em relação à saúde mental, somada a infância conturbada, justifica e/ou contribui para todas as ações do personagem Arthur Fleck/ Coringa"?

( ) concordo totalmente

( ) concordo parcialmente() discordo

- Você concorda com a frase: "Quanto maior a vulnerabilidade social, maior aprobabilidade do sujeito para cometer crimes"?

( ) concordo totalmente

( ) concordo parcialmente() discordo

- Você concorda com a frase: "O filme retrata a condição social de pessoas com doenças mentais na sociedade brasileira"?

( ) concordo totalmente

( ) concordo parcialmente() discordo

- Você concorda com a frase: “Todos os infratores da lei penal possuem algum tipo detranstorno ou doença mental"?

( ) concordo totalmente

( ) concordo parcialmente() discordo

- Você concorda com a frase: "O infrator da lei penal que possui transtorno mentaldeve ser tratado igual ao infrator da lei sem transtorno mental"?

( ) concordo totalmente

( ) concordo parcialmente() discordo

- Você concorda com a frase: "A lei penal deve ser endurecida para proteger o cidadãoque não comete infrações"?

( ) concordo totalmente

( ) concordo parcialmente() discordo

- Você concorda com a frase: "O Arthur Fleck/ Coringa deve ser responsabilizadojudicialmente por todos os seus atos"?

( ) concordo totalmente

( ) concordo parcialmente() discordo

- Você concorda com a frase: "Todos são iguais perante a lei"?() concordo totalmente

( ) concordo parcialmente() discordo 